meteorologists as that of an outstanding pioneer of the radio-sonde. Väisälä's association with aerology goes back to 1916 when he was appointed head of the kite station at Ilmala, Finland. In 1919 he became head of the aerological section of the Finnish Central Meteorological Office. After making a number of improvements to the earlier aerological observing methods he began to experiment with the Väisälä radio-sonde in 1931. This reached a stage of development which could be called entirely satisfactory by 1936. In 1944 Väisälä founded a company for manu facturing radio-sondes on a commercial scale, and at present it exports them to fifteen countries. But apart from his aerological activities Väisälä has pursued an active academic career, having been a teaching assistant and lecturer in meteorology at the Finnish Institute of Physics, and culminating in a personal extraordinary professorship in meteorology at the University of Helsinki, from which he retired in 1958 at the age of sixty-nine. It is announced in the journal of the Geophysical Society of Finland, Geophysica (8, No. 1; 1960), that, in order to commemorate the seventieth birthday of this outstanding Finnish scientist, the Society has struck a special medal with the inscription: "The Finnish Pioneer of Aerology".

\section{National Institute of Industrial Psychology :}

Dr. R. B. Buzzard

Dr. R. B. Buzzard has been appointed research director of the National Institute of Industrial Psychology. The Institute's programme of research is partly financed by grants from the Department of Scientific and Industrial Research. After graduating in physiology and qualifying in medicine, Dr. Buzzard spent ten years as a member of the Medical Research Council's scientific staff at the Experimental Psychology Laboratory in Cambridge and then, in 1953, transferred to the Council's Industrial Psychology Research Unit at University College, London. His work has been concerned with problems of research and application in industry and the armed services. They have included training interviewers, the development of personnel-selection procedures, refresher training of returned prisoners of war, and investigations into industrial injury, sickness and absence and the effects of working environments. $\mathrm{He}$ will bring to the Institute wide experience of investigation in fields where the gap between research and practice in industry tends to be greatest. In 1960 , he was awarded the Institute's Vernon Prize, which is given in alternate years to the investigator regarded as having carried out the most valuable research in industrial psychology and physiology.

C-E-I-R, Ltd.:

Prof. M. G. Kendall

Prof. M. G. Kendall is to join the Board of C.E.I-R (U.K.), Ltd., the computer research services organization. He will be responsible for the Departments of Mathematics, of Statistics and of Operational Research. He will work closely with Dr. Alexander S. Douglas, the director of technical services, whose divisional responsibilities include Departments of Computer Services, of Computer Technology and of Programming. Prof. Kendall is at present professor of statistics in the University of London (London School of Economies) and will vacate his chair on September 30. He received his mathematical training at the University of Cambridge, and entered the Administrative Class of the British Civil Service in
1930 to work in what was then the Ministry of Agriculture and Fisheries, becoming the head of the Economics Intelligence Branch. In 1940 he resigned from the Civil Service to become statistician to the Chamber of Shipping of the United Kingdom. He remained at the Chamber of Shipping until 1949, becoming joint assistant general manager in 1947 . Since leaving the Chamber of Shipping in 1949, Dr. Kendall has been professor of statistics in the University of London. Among his activities in the University and at the London School of Economies have been the creation and direction of the Division of Research Techniques. Its work in statistics, econometrics, social surveys, and in operational research is known and followed in every country of the world.

\section{Euratom : U.K. Nuclear Energy Attaché}

Mr. G. H. Gremnhalgh, of the United Kingdom Atomic Energy Authority, has been appointed nuclear energy attaché to the United Kingdom Delegation to the European Communities, to succeed Mr. D. H. Hill. He will be taking up his appointment in the near future. Mr. Greenhalgh, who is forty and a chemist by profession, was a member of the Extra-Mural Research Division at the Atomic Energy Research Establishment, Harwell, until 1956, when he was appointed scientific attaché to the British Embassy in Stockholm. In his new appointment, Mr. Greenhalgh will act as adviser on nuclear energy matters to the Head of the United Kingdom Delegation to the European Communities and will keep in touch with the various installations on the territory of the Community concerned with the peaceful uses of nuclear energy. The present nuclear energy attaché, Mr. Hill, will be leaving Brussels at the end of May to take up a post with the Authority's Reactor Group.

\section{Co-ordination of Research and Development of Sources of Energy}

IN a written answer in the House of Commons on May 16, the Minister of Power, Mr. R. Wood, said that his Advisory Council on Research and Development existed to co-ordinate research and development in the whole field of energy. Its terms of reference were: to advise the Minister on research and development in relation to his statutory duty of securing the effective and co-ordinated development of coal, petroleum and other sources of fuel and power in Great Britain, and of promoting economy and efficiency in the supply, distribution, use and consumption of fuel and power; to advise the Minister of new scientific and technical knowledge or application of knowledge which, in the Council's opinion, should be taken into account in the performance of his statutory duties; and to keep the whole field of fuel and power under continuous review with the object of identifying problems needing research and development and advising the Minister of those problems with the view of discussion with the industries concerned.

The members of the Council are: Lord Fleck (chairman); Capt. (E.) W. Gregson (deputy chairman); Mr. M. A. L. Banks, British Petroleum Co.; Dr. C. M. Cawley, Ministry of Power; Mr. T. B. Clark, Imperial Chemical Industries, Ltd.; Sir Josiah Eccles, Electricity Council; Mr. W. K. Hutchison, Gas Council; Dr. W. A. Macfarlane, National Indus trial Fuel Efficiency Service; Sir Harry Melville, Department of Scientific and Industrial Research; Mr. L. Rotherham, Central Electricity Generating 